\title{
Effects of powdery mildew infection on chloroplast and mitochondrial functions in rubber tree
}

\author{
Li-Feng Wang ${ }^{1}$, Meng Wang ${ }^{2} \&$ Yu Zhang ${ }^{2}$
}

${ }^{1}$ Key Laboratory of Biology and Genetic Resources of Rubber Tree, Ministry of Agriculture, State Key Laboratory Incubation Base for Cultivation and Physiology of Tropical Crops, Rubber Research Institute, Chinese Academy of Tropical Agricultural Sciences, Danzhou, Hainan 571737, China; ${ }^{2}$ Environment and Plant Protection College, Hainan University, Haikou, Hainan 570228, China

Author for correspondence: Yu Zhang, e-mail: yuzhang_rain@hainu.edu.cn

\begin{abstract}
Powdery mildew (Oidium heveae Steinm.) is one of the most important leaf diseases in rubber tree (Hevea brasiliensis). However, physiological and molecular processes associated with the Hevea-powdery mildew interaction are still unclear. In this study, effects of powdery mildew infection on the mitochondrial and chloroplast functions in rubber tree were comprehensively investigated. Powdery mildew damaged the structure and function of mitochondria prior to chloroplasts, causing inner and outer membranes disruption. The intact rate of mitochondria membrane was reduced from $70 \%$ in control leaves to $23.1 \%$ in the leaves at 5 days after inoculation (dai). Significant decreases in the activities of cytochrome c oxidase, NADH oxidation and malate dehydrogenase (MDH) were observed in the powdery mildew-infected leaves. Tricarboxylic acid cycle (TCA) and electron transfer capacity were seriously impaired after powdery mildew invasion. Chlorophyll (Chl) contents, maximal photochemical efficiency (Fv/Fm), actual photochemical efficiency of photosystem II (ФPSII), and electron transport rate (ETR) were dramatically decreased in the infected leaves from 10 dai. Our results provided new insights into understanding the mechanism of Hevea-powdery mildew interaction in rubber tree.
\end{abstract}

Key words: Hevea brasiliensis, mitochondria, photosynthesis, powdery mildew.

\section{INTRODUCTION}

Powdery mildews (Ascomycotina, Erysiphales) are obligate biotrophic plant pathogens that only grow on living hosts and cause damage in thousands of plant species (Glawe, 2008; Gadoury et al., 2012). Aspects of the etiology, epidemiology, and control of powdery mildew diseases are well documented in barley, wheat, grape, and several other crops (Fung et al., 2008; Kalinina et al., 2011; Gadoury et al., 2012). Rubber tree (Hevea brasiliensis Muell. Arg., family Euphorbiaceae) is the most important source of natural rubber for the manufacture of rubber products and timber (Bandurski \& Teas, 1957). This Amazonian (South America) tree species was introduced to tropical regions of Asia during the $19^{\text {th }}$ century, and since then rubber tree has been commercially grown in these regions. Powdery mildew (Oidium heveae Steinmann) is an important leaf disease in rubber plantations. Generally, it attacks the immature leaves when tree defoliates after the annual wintering, causing secondary leaf fall. Outbreak of this disease have been widely reported in Malaysia, India, Brazil, and Papua New Guinea (Mitra \& Mehta, 1938; Shaw, 1967). The severity of the disease varies with the pattern of wintering, leaf age, weather conditions, elevation, and susceptibility of the rubber tree clone. Hevea powdery mildew was firstly reported in the Hainan province of China in 1951, causing defoliation of young shoots, discoloration and curling on mature leaves, growth retardation and reduction in latex yield. Chemical protection with sulphur is a time and labour consuming process (Wastie, 1975).

To date, detailed morphological data and taxonomy of $O$. heveae are not fully understood (Thankamma, 1968; Limkaisang et al., 2006; Limkaisang et al., 2005). The lack of a robust infectivity assay for $O$. heveae in rubber tree hinders the development of an effective method to control this disease. In plant-microbe interactions, once a pathogen is recognized, the plant responds with the induction of a number of different defense responses (He et al., 2013). An important defense response is the hypersensitive response (HR), in which rapid, localized plant cell death prevents further pathogen spread (Mehdy, 1994). HR involves the induction of an oxidative burst at the plasma membrane that produces active oxygen species (AOS) such as superoxides that are rapidly converted to hydrogen peroxide (Wojtaszek, 1997). The rapid generation of AOS is a very early response to pathogen infection. It has been described in many plantpathogen interactions and considered a characteristic and common feature of HR leading to programmed cell death (Greenberg et al., 1994). In addition, aerobic metabolic processes such as respiration and photosynthesis unavoidably lead to the production of reactive oxygen species in mitochondria, chloroplasts, and peroxisomes (Apel \& Hirt, 
2004). Powdery mildew fungi attack the leaves of plants, inevitably affecting photosynthesis and respiration in the leaf tissue. Photorespiratory pathway and defense response to powdery mildew in chestnut rose (Huang et al., 2012), barley (Edwards, 1970; Williams \& Ayres, 1981) and sugar beets (Magyarosy et al., 1976) have been well documented. Hence, we reasoned that plant susceptibility to powdery mildew can be related to malfunctions of mitochondria and chloroplasts. In this study, a series of physiological indices related to mitochondrial and chloroplast activity were investigated extensively in powdery mildew-infected ruber trees, to better understand the physiological effects of the infection.

\section{MATERIALS AND METHODS}

\section{Plant material, fungal isolates and inoculation}

The grafted seedlings of rubber tree clone GT1 (original clone breed in Indonesia) were used to study chloroplast and mitochondrial functions after inoculation with powdery mildew. The source of rubber tree powdery mildew (Oidium heveae) was a local natural mixture collected in the rubber plantation of Danzhou, Hainan province, China $\left(19^{\circ} 51^{\prime} 51 \mathrm{~N}, 109^{\circ} 55^{\prime} 63 \mathrm{E}\right)$. The powdery mildew fungus were maintained on seedlings of highly susceptible rubber tree clone $\mathrm{RO} / \mathrm{PB} / 2$ at $23^{\circ} \mathrm{C}, 16 \mathrm{~h}$ day light, and $80 \%$ relative humidity. Inoculation was performed when the second unit leaf of GT1 was fully expanded. Fresh powdery mildew spores from the infected seedlings of $\mathrm{RO} / \mathrm{PB} / 2$ were inoculated to seedlings of GT1 with a camelhair brush. Seedlings of GT1 without inoculation were used as control, and kept in a separated illumination incubator to avoid infection by the fungus. The inoculated and control seedlings were grown at $25^{\circ} \mathrm{C}, 16 \mathrm{~h}$ day light, and $80 \%$ relative humidity in green house. Three batches of experiments were performed between March and May 2012. Six seedlings were used in each batch of experiments for treatment and control, respectively. Three leaves from each plant were used for the following assays. Each analysis had three technical replications. The inoculated and control leaves were collected at the indicated time points after treatment for further analysis.

\section{Mitochondria isolation}

Mitochondria isolation was performed on ice as described (Millar et al., 2001). Two grams of rubber tree leaves were ground in $5 \mathrm{~mL}$ of grinding medium $(0.3 \mathrm{M}$ mannitol, $50 \mathrm{mM}$ sodium pyrophosphate, $0.5 \%[\mathrm{w} / \mathrm{v}]$ bovine serum albumin [BSA], $0.5 \%[\mathrm{w} / \mathrm{v}]$ polyvinylpyrrolidone40, $2 \mathrm{mM}$ EGTA, $20 \mathrm{mM}$ cysteine, $\mathrm{pH}$ 8.0). The cell extract was separated by centrifugation at $1,000 \mathrm{~g}$ for $5 \mathrm{~min}$ at $4^{\circ} \mathrm{C}$. The supernatant was centrifuged again at $18,000 \mathrm{~g}$ for 15 min. The collected organelle pellet was washed by repeating the $1,000 \mathrm{~g}$ and $18,000 \mathrm{~g}$ centrifugation steps. The final organelle pellet was resuspended in mannitol wash buffer (0.3 M mannitol, $0.1 \%$ [w/v] BSA, $10 \mathrm{~mm}$ TES (N-tris [hydroxymethyl]-methyl-2-aminoethanesulfonic acid]$\mathrm{NaOH}, \mathrm{pH}$ 7.5) and loaded onto a Percoll step gradient consisting of 1:4:2 ratio, from bottom to top, of $40 \%, 23 \%$ and $18 \%$ Percoll in mannitol wash buffer. The gradients were centrifuged for $45 \mathrm{~min}$ at 40,000 g, and mitochondria were present as an opaque band at the $23 \%: 40 \%$ interface. The band was collected, concentrated, and washed by centrifugation at $15,000 \mathrm{~g}$ for $15 \mathrm{~min}$, and then loaded onto a self-forming Percoll gradient containing 28\% Percoll in sucrose wash buffer $(0.3 \mathrm{M}$ sucrose, $0.1 \%$ [w/v] BSA, 10 $\mathrm{mM}$ TES-NaOH, pH 7.5). After centrifugation at 40,000 $\mathrm{g}$ for $30 \mathrm{~min}$, mitochondria banded near the top of the gradient and peroxisomal material banded near the bottom of the gradient. The mitochondrial band was collected and again washed and concentrated by two centrifugation steps at $15,000 \mathrm{~g}$ for $15 \mathrm{~min}$ in mannitol wash buffer.

\section{Determination of mitochondrial integrity and stability}

The activity of MDH (EC 1.1.1.37) was determined by observing the absorption change in $1 \mathrm{~mL}$ mitochondria reaction mixture (50 mM Na-glycine $\mathrm{pH} 10.0,0.4 \mathrm{M}$ sucrose, $100 \mathrm{mM} \mathrm{L}$-malic acid and $2.5 \mathrm{mM} \mathrm{NAD}^{+}$) at $340 \mathrm{~nm}$ with a GE Ultrospec 2100 Pro UV/Vis spectrophotometer. The reaction was initiated by adding malic acid. When this reaction reached a steady state, $50 \mu \mathrm{L}$ of $5 \%$ Triton- 100 were added, and the reaction was continuously monitored for two hours. The integrity of the mitochondria was calculated by the changes of MDH activities with or without adding Triton, and calculated as follows:

Integrity $\%=\frac{(+ \text { Triton MDH activity })-(- \text { Triton MDH activity })}{+ \text { Triton MDH activity }} \times 100$

where "+ Triton" represents the total activity of the mitochondria and "-Triton" represents the broken mitochondrial activity.

\section{Mitochondrial staining and microscopy}

The mitochondria were stained with $0.02 \%$ Janus Green B in Rioger solution. The stained mitochondria were observed on a light microscope (Leika Microsystems).

\section{Cytochrome $c$ oxidase activity}

Cytochrome $c$ oxidase (EC1.9.3.1) activity was measured in a $1 \mathrm{~mL}$ reaction mixture containing $0.1 \mathrm{M}$ potassium phosphate buffer ( $\mathrm{pH}$ 7.0) and $13 \mu \mathrm{M}$ cytochrome c. The reaction was started by the addition of mitochondria, and changes in absorbance at $550 \mathrm{~nm}$ were recorded. The molar extinction coefficient of cytochrome $c$ at $550 \mathrm{~nm}$ is $1.35 \times 10^{4} \mathrm{~mol} \mathrm{~L}^{-1} \mathrm{~cm}^{-1}$.

\section{MDH activity}

MDH activity was measured by spectrophotometry at $340 \mathrm{~nm}$ (Glatthaar et al., 1974; Palmer et al., 1982; Noyes et al., 1974). The reaction was started by adding mitochondria in a $1 \mathrm{~mL}$ reaction mixture containing $50 \mathrm{mM}$ Na-glycine $\mathrm{pH}$ 10.0, $100 \mathrm{mM}$ L-malic acid and $2.5 \mathrm{mM} \mathrm{NAD}^{+}$. The 
molar extinction coefficient of NADH at $340 \mathrm{~nm}$ is $6.2 \times$ $10^{3} \mathrm{~mol} \mathrm{~L}^{-1} \mathrm{~cm}^{-1}$.

\section{Catalase (CAT) activity}

CAT activity was determined by continuous monitoring the decomposition of $\mathrm{H}_{2} \mathrm{O}_{2}$ at $240 \mathrm{~nm}$ (Mueller et al., 1997). The reaction mixture contained $100 \mathrm{mM}$ potassium phosphate buffer $\mathrm{pH} 7.0$ and $0.14 \mathrm{mM} \mathrm{H}_{2} \mathrm{O}_{2}$. The reaction was started by adding mitochondria into $1 \mathrm{~mL}$ of the reaction mixture, and absorbance at $240 \mathrm{~nm}$ was monitored on a spectrophotometer. The molar extinction coefficient of $\mathrm{H}_{2} \mathrm{O}_{2}$ at $240 \mathrm{~nm}$ is $36 \mathrm{~mol} \mathrm{~L}^{-1} \mathrm{~cm}^{-1}$.

\section{Mitochondrial NADH oxidation assay}

NADH oxidation by mitochondria was measured at $340 \mathrm{~nm}$ (Palmer \& Møller, 1982). The reaction mixture contained $0.3 \mathrm{M}$ sucrose, $10 \mathrm{mM}$ potassium phosphate, $50 \mathrm{mM} \mathrm{KCI}, 5 \mathrm{mM} \mathrm{MgCl}$ and $10 \mathrm{mM}$ Tris- $\mathrm{HCl} \mathrm{pH} 7.2$. Mitochondria were added to a $1 \mathrm{~mL}$ reaction mixture, and then NADH was added to start the reaction. The change of absorbance at $340 \mathrm{~nm}$ was monitored during this reaction.

\section{Analysis of chlorophyll contents}

Chlorophylls were extracted with $80 \%$ cold acetone from $0.1 \mathrm{~g}$ of fresh leaves. The extract was measured by spectrophotometry at $475 \mathrm{~nm}, 645 \mathrm{~nm}$ and $663 \mathrm{~nm}$, respectively. Specific chlorophyll contents were determined according to the method described by Lichtenthaler (1987).

\section{Modulated chlorophyll fluorescence}

Modulated chlorophyll fluorescence was measured in attached leaves at mid-day with a PAM-2500 portable fluorometer (Walz) connected to a computer with data acquisition software PamWin-3 (Walz). The experimental protocol was as described by Demmig-Adams et al. (1996). The minimal fluorescence level $\left(\mathrm{F}_{0}\right)$ in the darkadapted state was measured by the measuring modulated light, which was sufficiently low $\left(<0.1 \mu \mathrm{mol} \mathrm{m}^{-2} \mathrm{~s}^{-1}\right)$ not to induce any significant variable fluorescence. To determine the minimal fluorescence level during illumination $\left(\mathrm{F}_{0}{ }^{\prime}\right)$, a black cloth was rapidly placed around the leaf with a leaf-clip holder in the presence of far-red light $(7 \mu \mathrm{mol}$ $\mathrm{m}^{-2} \mathrm{~s}^{-1}$ ) in order to oxidize the photosystem II (PSII) centers fully. Upon darkening of the leaf, fluorescence dropped to the $\mathrm{F}_{0}$ ' level and immediately rose again within several seconds. The maximal fluorescence level in the dark-adapted state $\left(\mathrm{F}_{\mathrm{m}}\right)$ and the maximal fluorescence level during natural illumination $\left(\mathrm{F}_{\mathrm{m}}{ }^{\prime}\right)$ were measured by a 0.8 -s saturating pulse at $8,000 \mu \mathrm{mol} \mathrm{m} \mathrm{m}^{-2} \mathrm{~s}^{-1} . \mathrm{F}_{\mathrm{m}}$ was measured after 30 min of dark adaptation. $\mathrm{F}_{\mathrm{m}}$, and $\mathrm{F}_{\mathrm{s}}$ were measured when photosynthetic photon flux densities (PPFDs) were approximately 200 and $1,400 \mu \mathrm{mol} \mathrm{m}^{-2} \mathrm{~s}^{-1}$, respectively. Other parameters were calculated based on the parameters measured above.

\section{Isolation of chloroplasts}

Chloroplasts were isolated according to Edwards et al. (1979) with some modifications. Leaves were washed thoroughly with deionized water. Clean leaves were ground in a dark room at $4^{\circ} \mathrm{C}$ for $20 \mathrm{~s}$ with a blender in a grinding medium containing $0.33 \mathrm{M}$ sorbitol, $50 \mathrm{mM} 2-(\mathrm{N}-$ morpholino) ethanesulfonic acid (MES) $\mathrm{pH} 6.1,10 \mathrm{mM}$ $\mathrm{NaCl}, 2 \mathrm{mM} \mathrm{MgCl}, 2 \mathrm{mM}$ Na-EDTA, $0.5 \mathrm{mM} \mathrm{KH}_{2} \mathrm{PO}_{4}, 2$ $\mathrm{mM} \mathrm{Na}$ isoascorbate and $0.2 \%(\mathrm{w} / \mathrm{w}) \mathrm{BSA}$. The slurry was filtered through 500-, 195-, and 20- $\mu \mathrm{m}$ nylon mesh, and the filtrate was centrifugated at $300 \mathrm{~g}$ for $3 \mathrm{~min}$. Pellets were resuspended in the grinding medium and centrifuged at 5,000 $\mathrm{g}$ for $7 \mathrm{~min}$ to collect chloroplasts. The isolated chloroplasts were washed with the grinding medium and resuspended in the buffer which contained the same composition as the grinding medium except that the MES was replaced with $25 \mathrm{mM}$ HEPES-NaOH ( $\mathrm{pH}$ 7.6). The final concentration of chloroplasts was higher than $1 \mathrm{mg}$ chlorophyll $\mathrm{mL}^{-1}$, and stored at $-80^{\circ} \mathrm{C}$ until use.

\section{Analysis of soluble sugars}

Soluble sugars were measured according to the method reported by Creelman et al. (1990). One hundred milligrams of leaves were placed into $10 \mathrm{~mL}$ centrifuge tubes containing $5 \mathrm{~mL}$ of $80 \%$ alcohol, and were heated in water for $30 \mathrm{~min}$ at $80^{\circ} \mathrm{C}$. After cooling down to room temperature, the samples were centrifuged at $1,000 \mathrm{~g}$ for 10 min. Sugar content was determined by the phenol-sulfuric acid method.

\section{Analysis of malondialdehyde (MDA) content}

MDA content was assayed by the thiobarbituric acid (TBA) method with minor modifications (Aust et al., 1985). Five hundred milligrams of leaves were extracted with 5 $\mathrm{mL}$ of $5 \%$ trichloroacetic acid, and the homogenate was centrifuged at 3,000 g for $10 \mathrm{~min}$. The supernatant $(2 \mathrm{~mL})$ was transferred to a new tube, and $2 \mathrm{~mL}$ of $0.67 \%$ (w/v) TBA were added. The mixture was heated in a water bath for $30 \mathrm{~min}$ at $100^{\circ} \mathrm{C}$. Optical densities (OD) at $450 \mathrm{~nm}, 532$ $\mathrm{nm}$ and $600 \mathrm{~nm}$ were measured in a spectrophotometer.

\section{Proline content assay}

Proline content was determined according the method of Bates et al. (1973). Briefly, $0.5 \mathrm{~g}$ of leaves were homogenized in $10 \mathrm{~mL}$ of $3 \%$ sulfosalicylic acid. The filtered homogenate $(2 \mathrm{~mL})$ was treated sequentially with $2 \mathrm{~mL}$ acid ninhydrin, $2 \mathrm{~mL}$ glacial acetic acid, and $4 \mathrm{~mL}$ toluene. Absorbance of the colored solution was measured at $520 \mathrm{~nm}$ in a spectrophotometer.

\section{Statistical analysis}

All the obtained data was analyzed with IBM SPSS Statistics version 20.0 (IBM). One-way ANOVA with Tukey's test was used to assess probability levels $(P<0.01)$. Figures were drawn with OriginPro8.5.1 (Origin Lab Corporation). The means from three batches of experiments 
and the standard deviations (SD) were calculated.

\section{RESULTS}

Powdery mildew differentially affects chloroplast and mitochondrial functions in rubber tree

The powdery mildew fungi collected from rubber plantations could successfully infect the light green leaves of rubber tree clone GT1. The inoculated spores germinated and formed fresh conidia on the infected leaves at 5 dai. A curl phenotype with white, yellow and brown spots appeared on the infected leaves at 10 dai. As showed in Figure 1, at 5 dai and 10 dai, cytochrome c oxidase activities were decrease by $22 \%$ and $79 \%$ in the infected leaves comparing with the uninoculated control $(P<0.01)$, respectively. CAT is
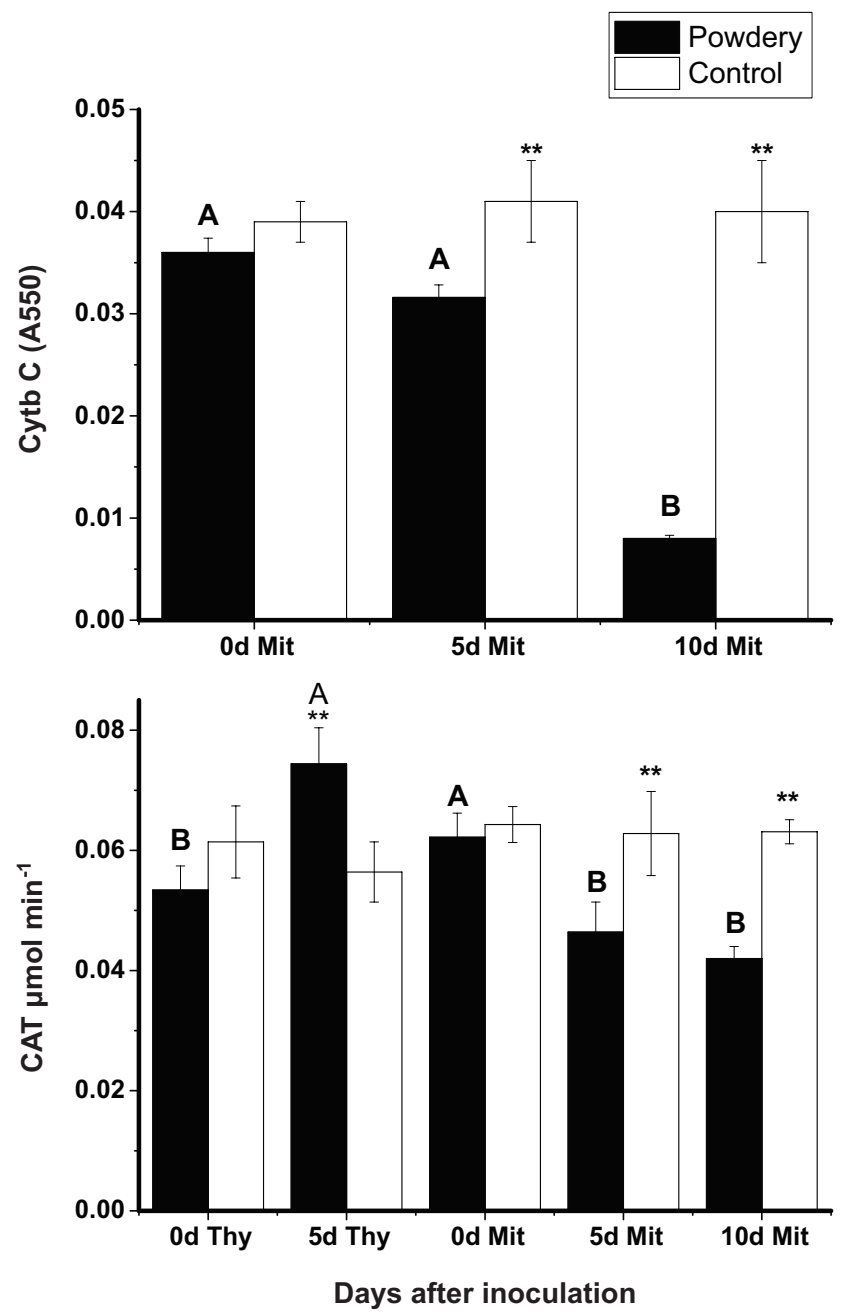

FIGURE 1- Changes of CAT and cytochrome $c$ oxidase enzyme activities in chloroplasts and mitochondria during powdery mildew infection. Thy, Chloroplast thylakoid membrane; Mit, Mitochondria. Bars with different letters showed significant differences at $P<0.01$. Significant differences at $P<0.01$ level between powdery mildew inoculation and corresponding control were marked with “***". a common enzyme found in nearly all living organisms that are exposed to oxygen, where it functions to catalyze the decomposition of hydrogen peroxide to water and oxygen. After powdery mildew infection, CAT activity was increased in chloroplasts, but decreased in mitochondria at 5 and 10 dai (Figure 1). In the control sample, activity of MDH in chloroplasts was 2 -fold higher than that in mitochondria (Figure 2). However, in the infected leaves, the activity of MDH both in chloroplasts and mitochondria decreased sharply at 5 dai, suggesting powdery mildew interrupted the tricarboxylic acid cycle (TCA) cycle in mitochondria. The NADH oxidation was dramatically decreased in mitochondria at 5 and 10 dai $(P<0.01)$, whereas no NADH activity was dramatically decreased in mitochondria at 5 and 10 dai $(P<0.01)$, whereas a more modest decrease in NADH activity was found in chloroplasts at 5 dai (Figure 2 ). These indicated powdery mildew infection in rubber

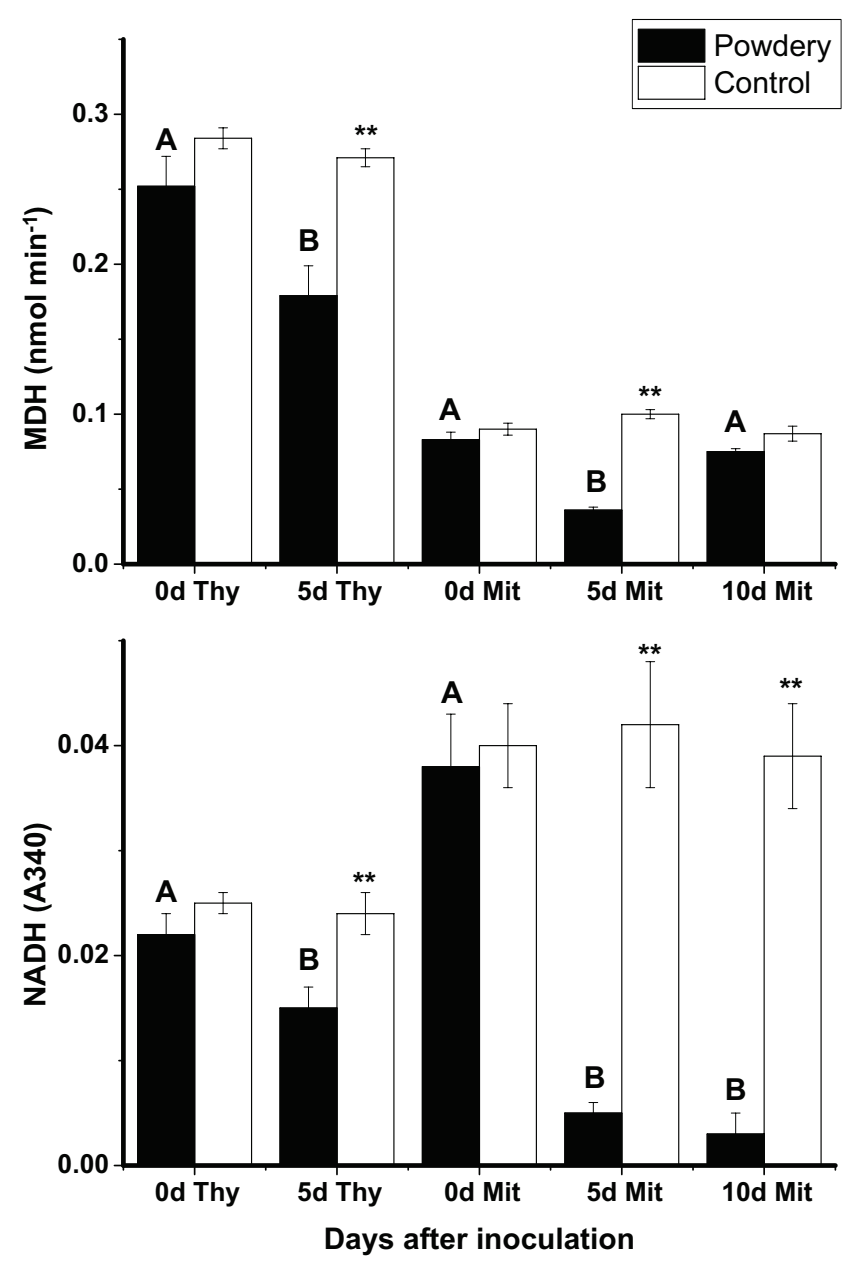

FIGURE 2 - Changes of MDH and NADH enzyme activities in chloroplasts and mitochondria during powdery mildew infection. Thy, Chloroplast thylakoid membrane; Mit, Mitochondria. Bars with different letters showed significant differences at $P<0.01$. Significant differences at $P<0.01$ level between powdery mildew inoculation and corresponding control were marked with "**”. 
tree damaged mitochondria more seriously and earlier than chloroplasts. Powdery mildew showed destructive effect on the integrity of mitochondria. The mitochondrial integrity was decrease from $63 \%$ in the control leaves to $23 \%$ and $11 \%$ in the leaves of 5 and 10 dai, respectively (Figure 3).

\section{Powdery mildew affected chlorophyll content and} chlorophyll $a$ fluorescence parameters

Powdery mildew reduced chlorophyll content in rubber tree at 5 dai. As the reduction of $\mathrm{Chl} b$ was lower than $\mathrm{Chl}$ a, the ratio of $\mathrm{Chl} \mathrm{a} / \mathrm{b}$ decreased (Figures 4 and 5). Most $\mathrm{Chl}$ a is located in chlorophyll-protein complexes at the reaction center, while $\mathrm{Chl} b$ is located in light harvesting chlorophyll-protein complexes. The degradation of the photosynthetic electron transfer chain began with light harvesting chlorophyll-protein complexes resulting in the degradation of $\mathrm{Chl} \mathrm{b}$. In the most severely damaged leaves, more $\beta$-carotene was generated for quenching extra light energy at 5 and 10 dai $(P<0.01)$ (Figure 4$)$.

The $\mathrm{Fv} / \mathrm{Fm}$ at 5 and 10 dai were $7 \%$ and $16 \%$ lower than that of uninoculated control plants, respectively (Figure 6). In the inoculated plants, ETR and DPSII were also decreased significantly at 10 dai $(P<0.01)$. However, non-photochemical quenching (NPQ) was significantly increased in the inoculated leaves comparing with that in the control leaves at 10 dai $(P<0.01)$ (Figure 7). These results suggested that after the destruction of photosynthesis systems, light energy absorbed by chloroplasts cannot be transfered to photosystem I as photochemical quenching. Most of the excited energy was dissipated as NPQ. These results were consistent with the increase of $\beta$-carotene contents which can quench excess light energy.

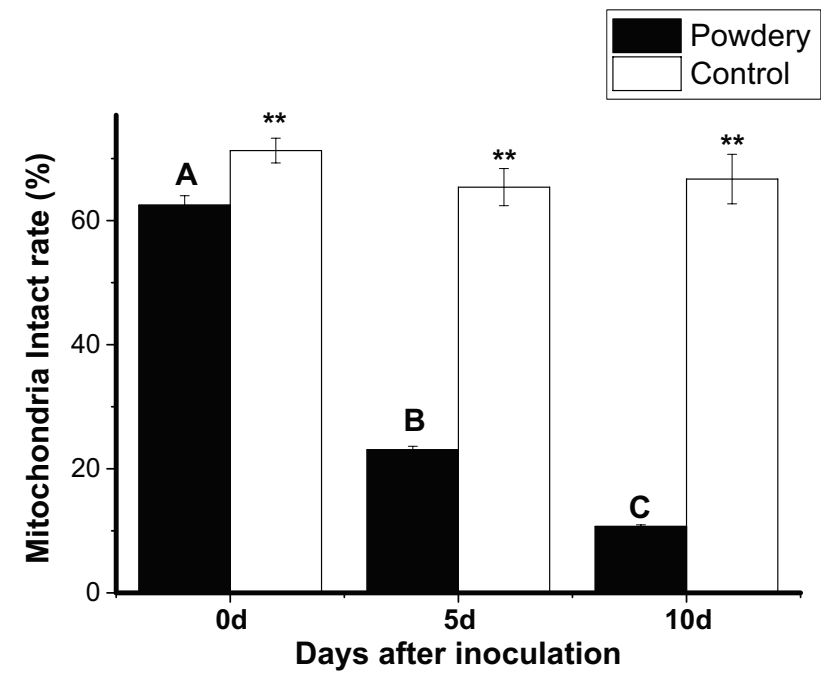

FIGURE 3 - The effect of powdery mildew on the integrity of mitochondria. Bars with different letters showed significant differences at $P<0.01$. Significant differences at $P<0.01$ level between powdery mildew inoculation and corresponding control were marked with “***.
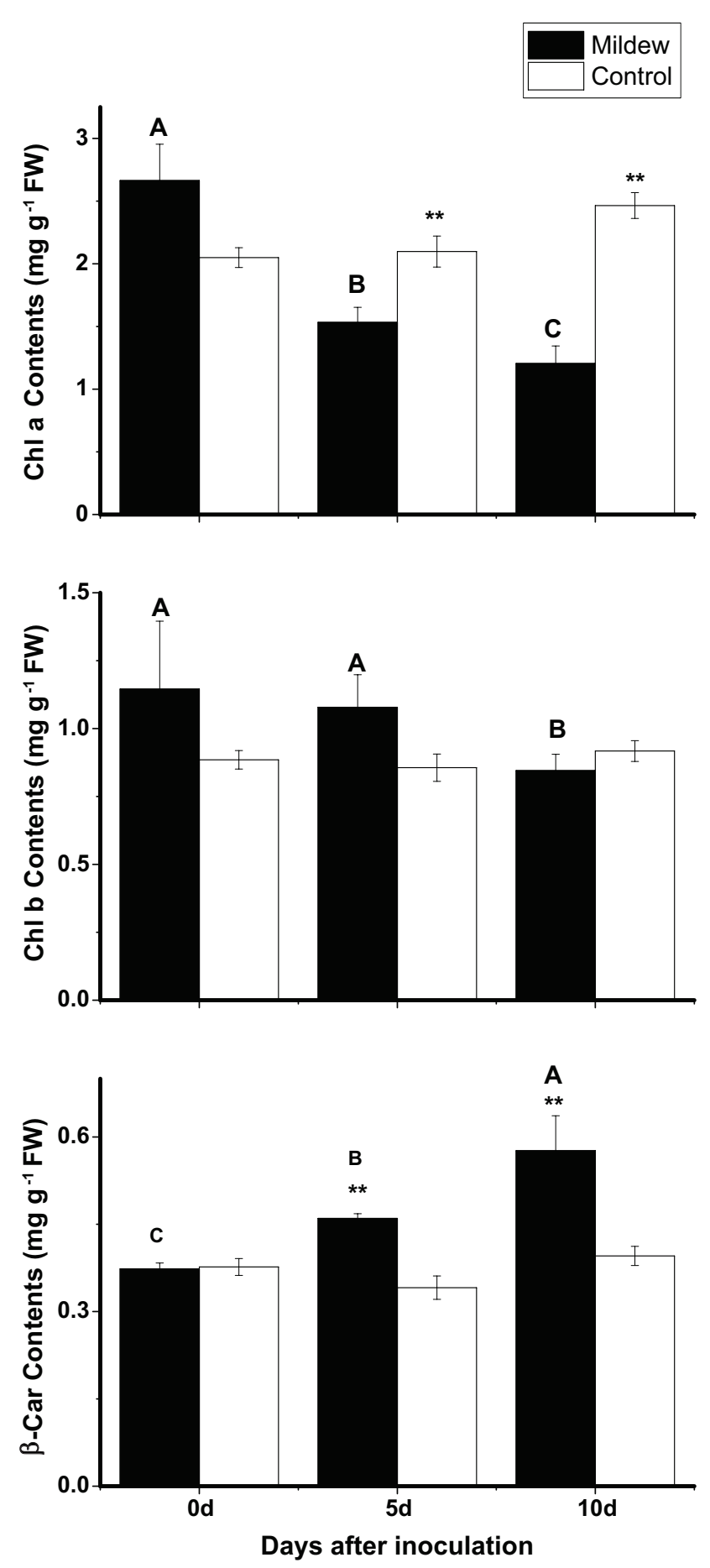

FIGURE 4 - Changes of $\mathrm{Chl} \mathrm{a}, \mathrm{b}$ and $\beta$-carotene contents after inoculation with powdery mildew. Bars with different letters showed significant differences at $P<0.01$. Significant differences at $P<0.01$ level between powdery mildew inoculation and corresponding control were marked with "***".

\section{Powdery mildew affected stress indices}

Proline accumulates in plants under stress conditions such as drought, salt, etc. Besides osmoregulation, 


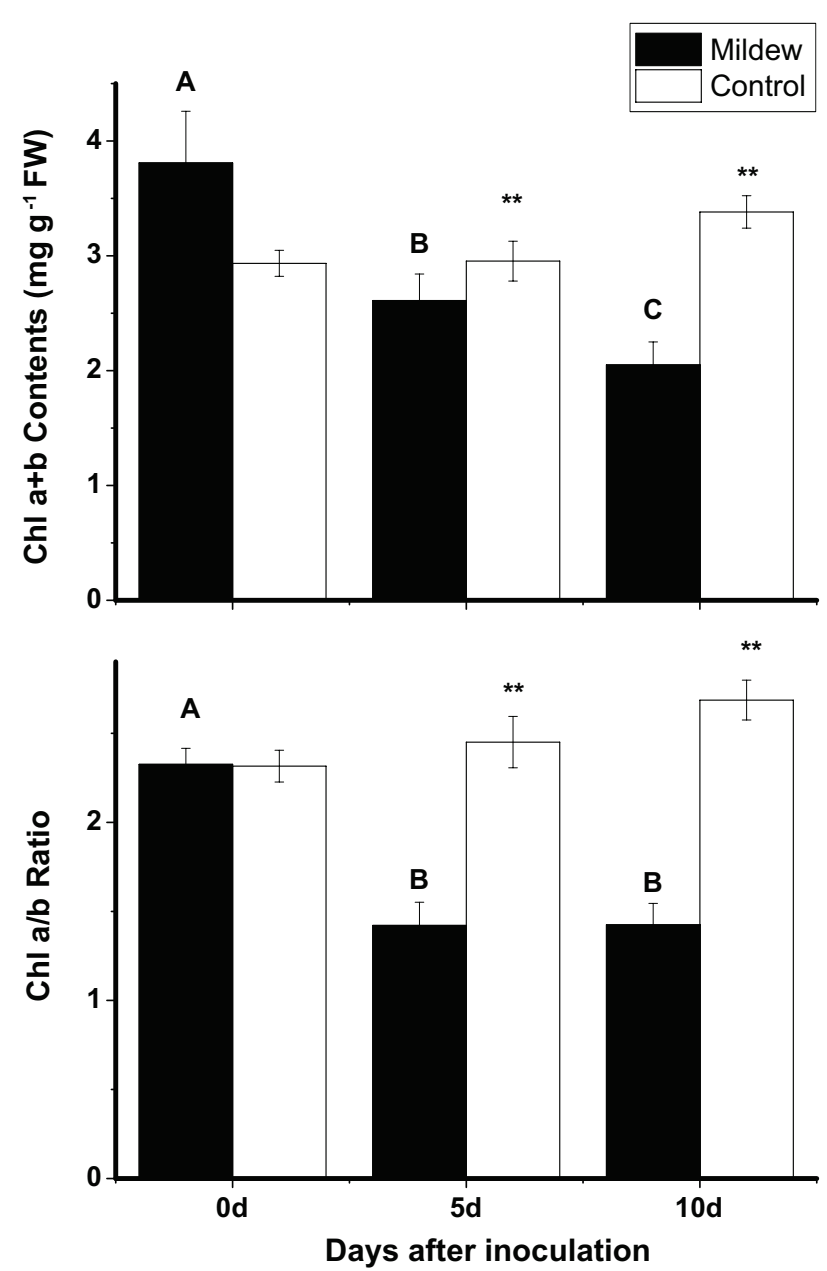

FIGURE 5 - Changes of total chlorophyll content and Chl a/b ratio after inoculation with powdery mildew. Bars with different letters showed significant differences at $P<0.01$. Significant differences at $P<0.01$ level between powdery mildew inoculation and corresponding control were marked with "***".

proline plays important roles in stabilizing the structure of macromolecules, reducing cell acidity, detoxifying ammonia, and used as energy base in the regulation of cellular redox potential. After rubber tree infection by powdery mildew proline content was increased at 5 dai, but was decreased at 10 dai (Figure 8). MDA is generated from reactive oxygen species, and as such is assayed in vivo as a bio-marker of oxidative stress. The MDA content in the leaves at 5 and 10 dai was 3.2- and 3.6-fold higher than that in the control leaves, respectively (Figure 8). Soluble sugars are involved in the responses to a number of stresses, and were significantly reduced in powdery mildew infected rubber tree leaves at 5 and 10 dai $(P<0.01)$.

\section{DISCUSSION}

Powdery mildew of rubber tree causes nearly $20 \%$ reduction in latex production in China annually. The copper-
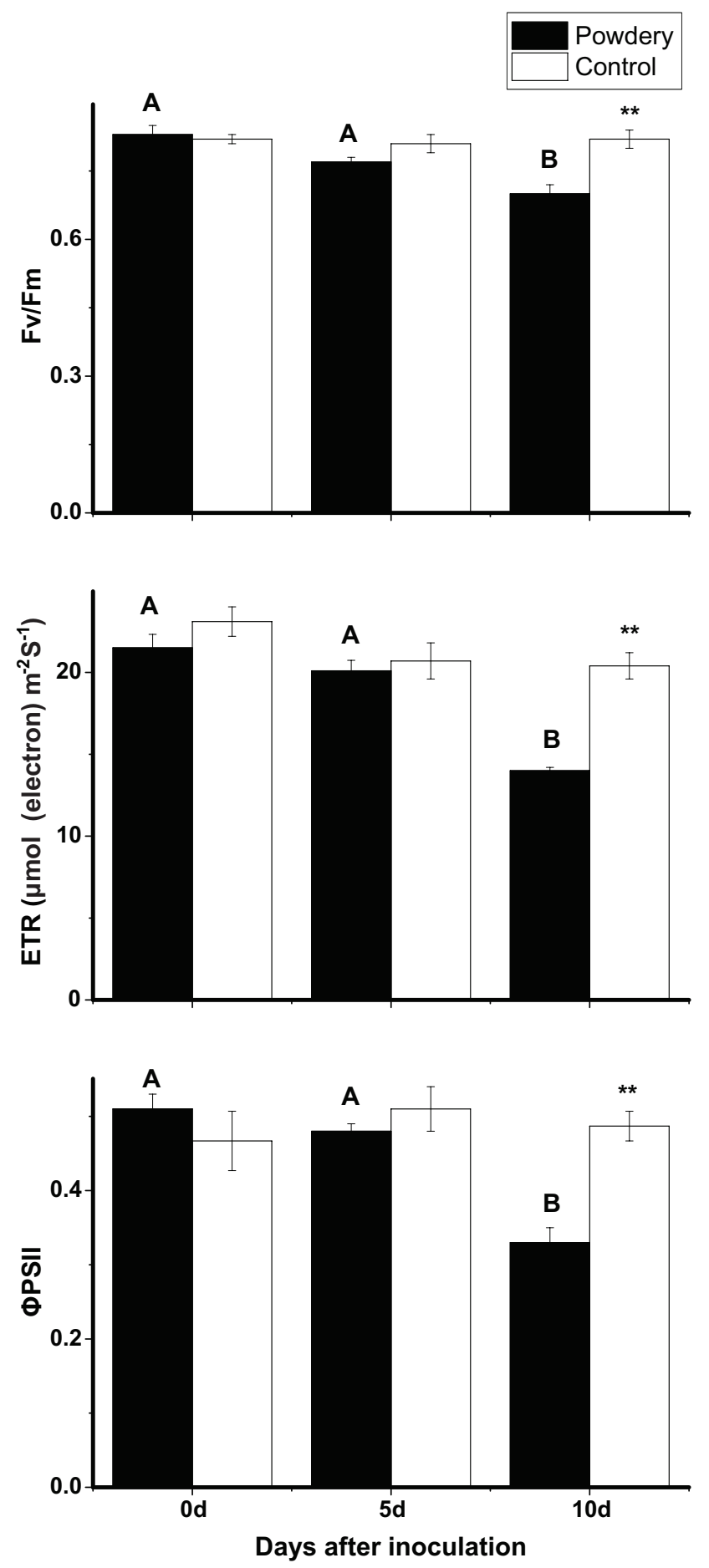

FIGURE 6 - Change of chlorophyll $a$ fluorescence parameters Fv/ Fm, ETR and ФPSII. Bars with different letters showed significant differences at $P<0.01$. Significant differences at $P<0.01$ level between powdery mildew inoculation and corresponding control were marked with "**".

brown and light green leaflets are more susceptible than dark green leaves. White powdery patches appear on both leaf surfaces, but especially on the lower leaf surface near the veins as the fungal hyphae grow radially to form extensive 

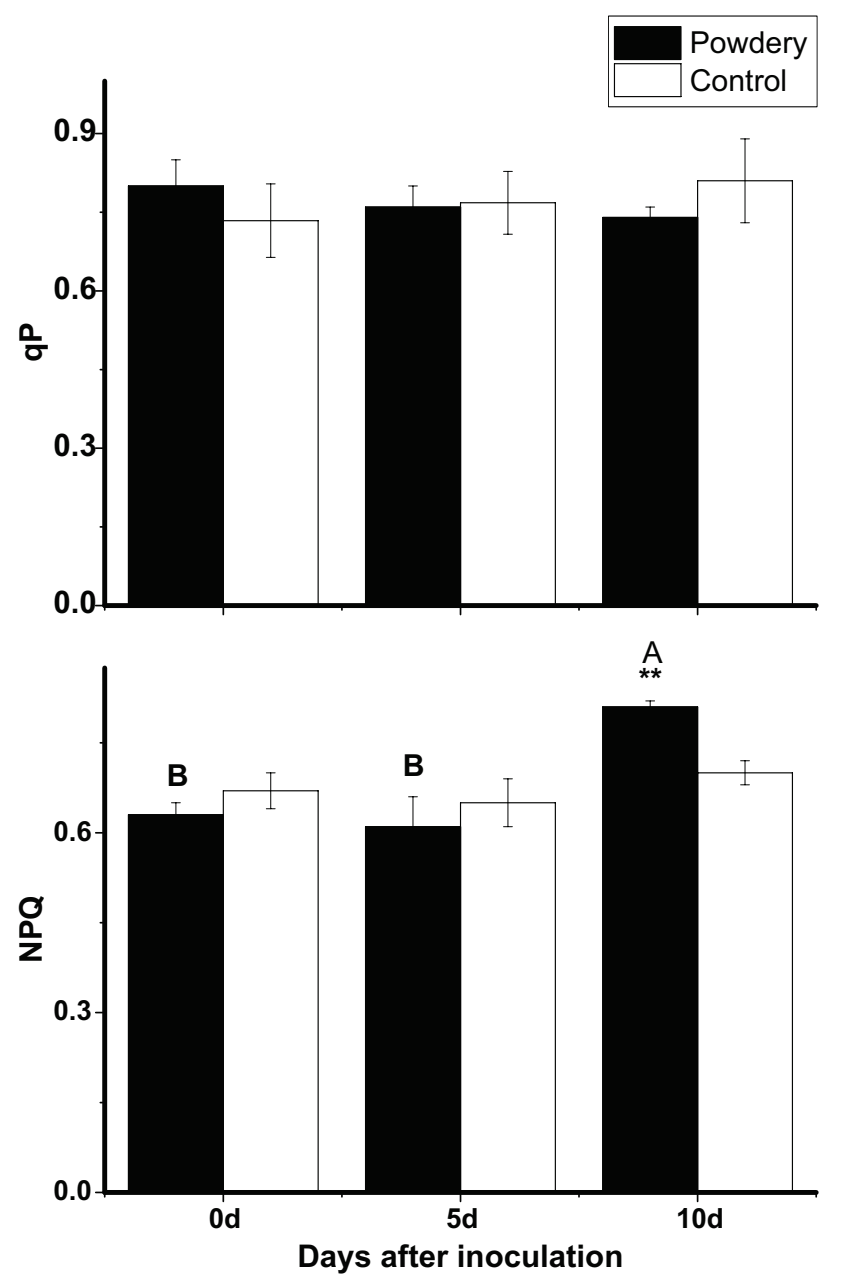

FIGURE 7 - Change of chlorophyll $a$ fluorescence parameters $\mathrm{qP}$ and NPQ. Bars with different letters showed significant differences at $P<0.01$. Significant differences at $P<0.01$ level between powdery mildew inoculation and corresponding control were marked with “**”.

circular colonies, even covering the entire leaf surface with spores. After penetration into the host cells, powdery mildew fungi obtain nutrients and water from host cells to finish its life cycle (Glawe, 2008), and do not kill the leaf cells in the short term. The biphasic inhibition of photosynthesis in powdery mildew-infected barley leaves suggested a stimulation in infected host tissue photosynthesis during the early stages of the disease followed by a rapid decline in activity (Edwards, 1970). This was in accordance with our findings in this study. The straight decline in chlorophyll content indicated that powdery mildew infection had a severe impact on photosynthetic efficiency of rubber tree leaves. However, the compensation by increase of $\beta$-carotene content can quench more excited energy accompanied by an increase in NPQ (Gilmore \& Yamamoto, 1991). Fv/ Fm, defined as maximum yield of primary photochemistry, is almost constant (0.832) for many different species
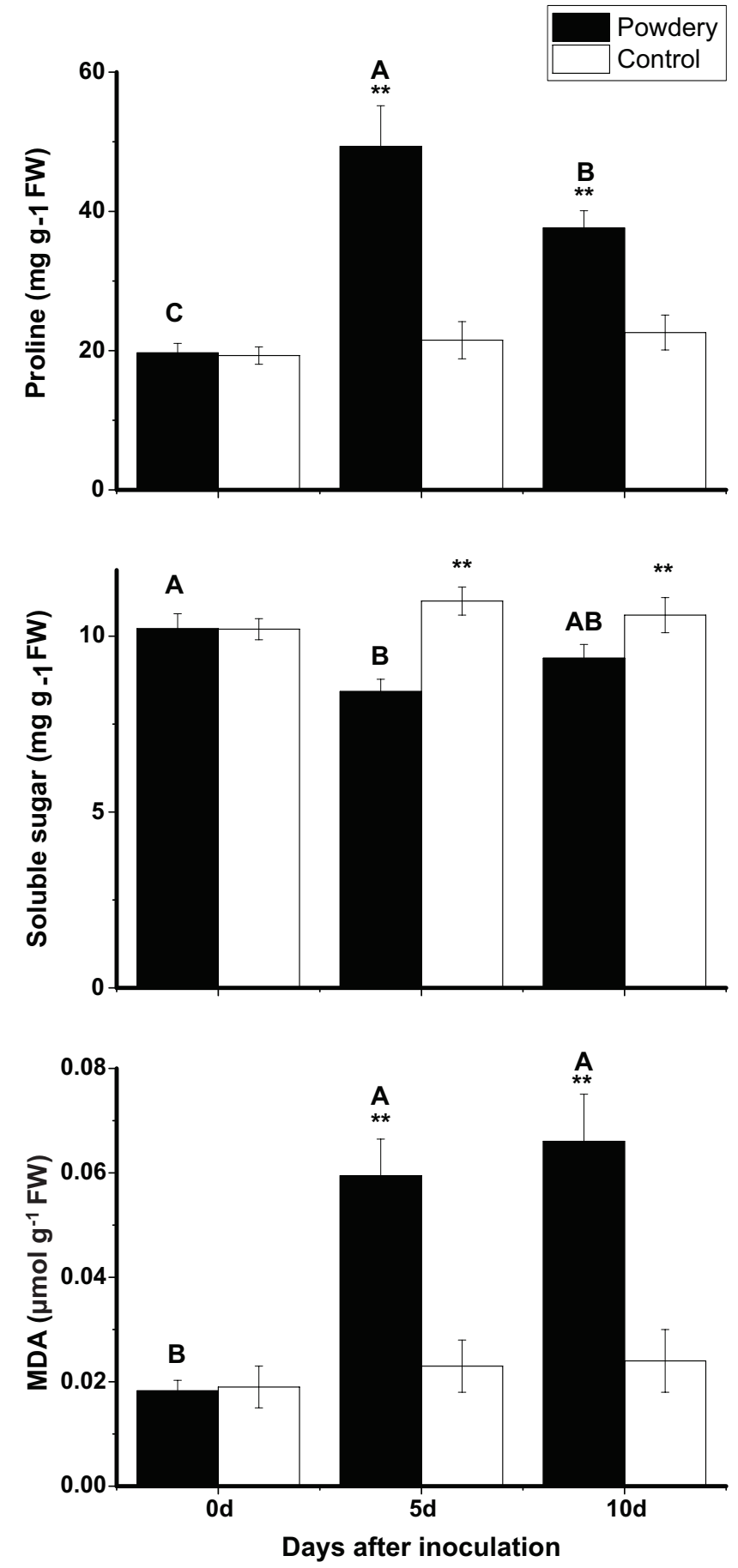

FIGURE 8 - Physiological response to powdery mildew infection in rubber tree leaves. Bars with different letters showed significant differences at $P<0.01$. Significant differences at $P<0.01$ level between powdery mildew inoculation and corresponding control were marked with "***".

measured under non-stressed conditions. The reduction of Fv/Fm under stress conditions makes it a useful indicator of damage caused to PSII complexes (Krause \& Weis, 1991). Our findings showed that ETR and Fv/Fm were slightly 
decreased at 5 dai, and a significant decrease was observed at 10 dai. These were in accordance with the severe infection phenotype observed at 10 dai. NPQ reflects the activation of non-photochemical processes during the light period, mostly leading to non-radiative energy dissipation as heat (Roháček, 2002). NPQ is induced by changes in the transthylakoid $\mathrm{pH}$ gradient, state transitions and photo inhibitory processes. The increase in NPQ was positively related to $\beta$-carotene and xanthophyll content. Powdery mildew infection may have damaged the thylakoid membranes, resulting in the failure in effective energy use by PSII reaction centers. Excited energy was quenched as NPQ, such as heat, possibly to protect thylakoid membranes from damage. The reduction of sugar content indicated the reduction of $\mathrm{CO}_{2}$ carboxylation and starch formation (Smith et al., 2005). The conversion between sugar and starch is another signal pathway in plant stress response (Rolland et al., 2006; Smeekens, 2000).

Powdery mildew infection affected mitochondrial structure and function more severely than those in chloroplasts. The integrity of mitochondrial membranes was reduced by nearly $80 \%$ at 10 dai compared to the uninfected control leaves. Since mitochondria are an important location of the conversion of AOS to $\mathrm{H}_{2} \mathrm{O}_{2}$ by SOD, their breakdown inevitably increases AOS content (Venditti et al., 2010). Oxidative damage in lipids, proteins, and DNA has been suggested as indexes of oxidative stress in biological systems. MDA, a simple indicator and byproduct of lipid peroxidation, was increased significantly in powdery mildew infected leaves. The same pattern was observed for proline content, an indicator of osmotic stress. Various metabolic reactions and regulations directly link soluble sugars with the production rates of reactive oxygen species, such as mitochondrial respiration and photosynthesis regulation, or, conversely, with anti-oxidative processes, such as the oxidative pentosephosphate pathway and carotenoid biosynthesis (Couee et al., 2006). Decreases of soluble sugars involved in abiotic and biotic stresses, such as chilling, herbicide injury, or pathogen attack, are related to changes in reactive oxygen species balance. Our results showed significant correlation between a decrease of soluble sugars and an increase of ROS contents.

To date, detailed morphological data and taxonomy of Hevea powdery mildew, as well as the mechanisms of powdery mildew infection and resistance in rubber tree are mostly unknown. Our research investigated the effects of powdery mildew infection on the mitochondrial and chloroplast functions in rubber tree. Takingww our results together, it is reasonable to deduce that the infection negatively affected mitochondria prior to and more severly than chloroplasts, which resulted in the release of ROS, and subsequently led to the death of leaves. These results will lay foundations for further research on the mechanism of Hevea-powdery mildew interactions at the transcriptome and proteome levels.

\section{ACKNOWLEDGEMENTS}

This work was supported by the Earmarked Fund for Modern Agro-industry Technology Research System (CARS-34-GW8), the Ministry of Agriculture Tropical Crops Special Item (12RZBC-11), the Special Fund for Improving Comprehensive Strength of Midwest Colleges and Universities, and the Graduate Innovation Research Projects of Hainan Province (Hyb2012-4).

\section{REFERENCES}

Apel K, Hirt H (2004) Reactive oxygen species: Metabolism, oxidative stress, and signal transduction. Annual Review of Plant Biology 55:373-399.

Aust SD, Morehouse LA, Thomas CE (1985) Role of metals in oxygen radical reactions. Journal of Free Radical Biology \& Medicine 1:3-25.

Bandurski RS, Teas HJ (1957) Rubber biosynthesis in latex of Hevea brasiliensis. Plant Physiology 32:643-648.

Bates LS, Waldren RP, Teare ID (1973) Rapid determination of free proline for water-stress studies. Plant and Soil 39:205-207.

Couee I, Sulmon C, Gouesbet G, El Amrani A (2006) Involvement of soluble sugars in reactive oxygen species balance and responses to oxidative stress in plants. Journal of Experimental Botany $57: 449-459$

Creelman RA, Mason HS, Bensen RJ, Boyer JS, Mullet JE (1990) Water deficit and abscisic acid cause differential inhibition of shoot versus root growth in soybean seedlings: Analysis of growth, sugar accumulation, and gene expression. Plant Physiology 92:205214.

Demmig-Adams B, Adams III WW, Barker DH, Logan BA, Bowling DR, Verhoeven AS (1996) Using chlorophyll fluorescence to assess the fraction of absorbed light allocated to thermal dissipation of excess excitation. Physiologia Plantarum 98:253-264.

Dubois M, Gilles KA, Hamilton JK, Rebers PA, Smith F (1956) Colorimetric method for determination of sugars and related substances. Analytical Chemistry 28:350-356.

Edwards GE, Lilley RMC, Craig S, Hatch MD (1979) Isolation of intact and functional chloroplasts from mesophyll and bundle sheath protoplasts of the $\mathrm{C} 4$ plant Panicum miliaceum. Plant Physiology 63:821-827.

Edwards HH (1970) Biphasic inhibition of photosynthesis in powdery mildewed barley. Plant Physiology 45:594-597.

Fung RW, Gonzalo M, Fekete C, Kovacs, LG, He Y, Marsh E, McIntyre LM, Schachtman DP, Qiu W (2008) Powdery mildew induces defense-oriented reprogramming of the transcriptome in a susceptible but not in a resistant grapevine. Plant Physiology 146:236-249.

Gadoury DM, Cadle-Davidson L, Wilcox WF, Dry IB, Seem RC, Milgroom MG (2012) Grapevine powdery mildew (Erysiphe necator): A fascinating system for the study of the biology, ecology and epidemiology of an obligate biotroph. Molecular Plant Pathology 13:1-16. 
Gilmore AM, Yamamoto HY (1991) Zeaxanthin formation and energy-dependent fluorescence quenching in pea chloroplasts under artificially mediated linear and cyclic electron transport. Plant Physiology 96:635-643.

Glatthaar BE, Barbarash GR, Noyes BE, Banaszak LJ, Bradshaw RA (1974) The preparation of the cytoplasmic and mitochondrial forms of malate dehydrogenase and aspartate aminotransferase from pig heart by a single procedure. Analytical Biochemistry 57:432-451.

Glawe DA (2008) The powdery mildews: A review of the world's most familiar (yet poorly known) plant pathogens. Annual Review of Phytopathology 46:27-51.

Greenberg JT, Guo A, Klessig DF, Ausubel FM (1994) Programmed cell death in plants: A pathogen-triggered response activated coordinately with multiple defense functions. Cell 77:551-563.

He P, Qin H, Wu M, Wu B, Wei J, Wang D (2013) Identification of genes differentially expressed in the roots of rubber tree (Hevea brasiliensis Muell. Arg.) in response to phosphorus deficiency. Molecular Biology Reports 40:1397-1405.

Huang M, Xu Q, Deng X (2012) The photorespiratory pathway is involved in the defense response to powdery mildew infection in chestnut rose. Molecular Biology Reports 39:8187-8195.

Kalinina O, Zeller SL, Schmid B (2011). Competitive performance of transgenic wheat resistant to powdery mildew. PLoS One 6: e28091.

Krause GH, Weis E (1991) Chlorophyll fluorescence and photosynthesis: The basics. Annual Review of Plant Physiology \& Plant Molecular Biology 42:313-349.

Lichtenthaler HK (1987) Chlorophylls and carotenoids: Pigments of photosynthetic biomembranes. Methods in Enzymology 148: 50-382.

Limkaisang S, Cunnington JH, Wui LK, Salleh B, Sato Y, Divarangkoon R, Fangfuk W, To-anun C, Takamatsu S (2006) Molecular phylogenetic analyses reveal a close relationship between powdery mildew fungi on some tropical trees and Erysiphe alphitoides, an oak powdery mildew. Mycoscience 47:327-335.

Limkaisang S, Kom-Un S, Furtado EL, Liew KW, Salleh B, Sato Y, Takamatsu S (2005) Molecular phylogenetic and morphological analyses of Oidium heveae, a powdery mildew of rubber tree. Mycoscience 46:220-226.

Magyarosy AC, Schurmann P, Buchanan BB (1976) Effect of powdery mildew infection on photosynthesis by leaves and chloroplasts of sugar beets. Plant Physiology 57:486-489.
Mehdy MC (1994) Active oxygen species in plant defense against pathogens. Plant Physiology 105:467-472.

Millar AH, Sweetlove LJ, Giege P, Leaver CJ (2001) Analysis of the Arabidopsis mitochondrial proteome. Plant Physiology 127:1711-1727.

Mitra M, Mehta PR (1938) Some leaf diseases of Hevea brasiliensis new to India. Indian Journal of Agricultural Science 8:185-188.

Mueller S, Riedel H-D, Stremmel W (1997) Determination of catalase activity at physiological hydrogen peroxide concentrations. Analytical Biochemistry 245:55-60.

Noyes BE, Glatthaar BE, Garavelli JS, Bradshaw RA (1974) Structural and functional similarities between mitochondrial malate dehydrogenase and L-3-hydroxyacyl CoA dehydrogenase. Proceedings of the National Academy of Sciences, USA 71:13341338.

Palmer JM, Møller IM (1982) Regulation of NAD(P)H dehydrogenases in plant mitochondria. Trends in Biochemical Sciences 7:258-261.

Palmer JM, Schwitzguebel JP, Møller IM (1982) Regulation of malate oxidation in plant mitochondria: Response to rotenone and exogenous NAD ${ }^{+}$. Biochemical Journal 208:703-711.

Roháček K (2002) Chlorophyll fluorescence parameters: The definitions, photosynthetic meaning, and mutual relationships. Photosynthetica 40:13-29.

Rolland F, Baena-Gonzalez E, Sheen J (2006) Sugar sensing and signaling in plants: Conserved and novel mechanisms. Annual Review of Plant Biology 57:675-709.

Shaw DE (1967) Powdery mildew of rubber in Papua. Papua and New Guinea Agricultural Journal 19:140-146.

Smeekens S (2000) Sugar-induced signal transduction in plants. Annual Review of Plant Biology 51:49-81.

Smith AM, Zeeman SC, Smith SM (2005) Starch degradation. Annual Review of Plant Biology 56:73-98.

Thankamma L (1968) Bixa orellana, an alternative host of Oidium heveae Stein. Rubber Board Bulletin 10:38-39.

Venditti P, Di Stefano L, Di Meo S (2010) Oxidative stress in cold-induced hyperthyroid state. Journal of Experimental Biology 213:2899-2911.

Wastie RL (1975) Diseases of rubber and their control. International Journal of Pest Management 21:268-288.

Wojtaszek P (1997) Mechanisms for the generation of reactive oxygen species in plant defence response. Acta Physiologiae Plantarum 19:581-589. 